\begin{tabular}{|c|c|c|c|c|c|c|c|c|}
\hline & Case 1 & Case 2 & Case 3 & Case 4 & Case 5 & Case 6 & Case 7 & Case 8 \\
\hline Diagnosis & UC & UC & UC & UC & UC & UC & UC & Crohns \\
\hline Dose thiopurine/allopurinol & $\begin{array}{l}\text { AZA } 50 \mathrm{mg} \\
\text { Allo } 100 \mathrm{mg}\end{array}$ & $\begin{array}{l}\text { AZA } 25 \mathrm{mg} 5 \mathrm{~d} / 50 \mathrm{mg} 2 \mathrm{~d} \text {, } \\
\text { Allo } 10 \mathrm{mg}\end{array}$ & $\begin{array}{l}\text { AZA } 25 \mathrm{mg} 5 \mathrm{~d} / 50 \mathrm{mg} 2 \mathrm{~d} \text {, } \\
\text { Allo } 100 \mathrm{mg}\end{array}$ & $\begin{array}{l}\text { AZA } 50 \mathrm{mg} \\
\text { Allo } 200 \mathrm{mg}\end{array}$ & $\begin{array}{l}6 \mathrm{MP} 50 \mathrm{mg} 5 \mathrm{~d} \text {, } \\
\text { Allo } 100 \mathrm{mg}\end{array}$ & $\begin{array}{l}6 \mathrm{MP} 50 \mathrm{mg} \mathrm{5d} \text {, } \\
\text { Allo } 100 \mathrm{mg}\end{array}$ & $\begin{array}{l}\text { 6MP } 25 \mathrm{mg} \mathrm{3d} \text {, } \\
\text { Allo } 100 \mathrm{mg}\end{array}$ & $\begin{array}{l}\text { 6MP } 50 \mathrm{mg} \text { 6d, } \\
\text { Allo } 100 \mathrm{mg}\end{array}$ \\
\hline $\begin{array}{l}\text { Duration of pre-pregnancy } \\
\text { co-therapy (months) }\end{array}$ & 6 & 19 & 1 & 12 & 14 & 6 & 15 & 24 \\
\hline Age at pregnancy (years) & 21 & 24 & 34 & 31 & 32 & 36 & 32 & 29 \\
\hline Number of flares in pregnancy & 0 & 1 & 0 & 0 & 0 & 0 & 0 & 0 \\
\hline Gestation at delivery (weeks) & 41 & $38+1$ & $39+4$ & $40+3$ & 38 & 39 & 34 & 38 \\
\hline Mode of delivery & SVD & C-section & C-section & SVD & SVD & SVD & C-section & C-section \\
\hline Fetal birth weight & $3.5 \mathrm{~kg}$ & $2.94 \mathrm{~kg}$ & $3.42 \mathrm{~kg}$ & $3.95 \mathrm{~kg}$ & $3.75 \mathrm{~kg}$ & $3.0 \mathrm{~kg}$ & $2.91 \mathrm{~kg}$ & $3.51 \mathrm{~kg}$ \\
\hline
\end{tabular}

Methods Patients were retrospectively identified at two hospitals in the UK and in Australia, using our local IBD databases. All pregnancies of co-therapy patients were included. TPMT activity and pre-pregnancy weight were used to calculate thiopurine dosing. Data regarding pregnancy and fetal outcomes were collected from patient notes.

Results Eleven females on co-therapy became pregnant, totalling twelve pregnancies with eight live births (Table 1) and four ongoing pregnancies. There were no reported terminations, miscarriages or spontaneous pre-term deliveries ( $<37$ weeks). Four patients gave birth by spontaneous vaginal delivery (SVD); four by Caesarean section (C-section). There were no low birth weight $(<2.5 \mathrm{~kg})$ babies. The APGAR scores of all babies were normal and no congenital malformations were identified either on fetal ultrasound scans or on neonate checks. The median duration of followup of babies was 6.5 months with no indication of morbidity.

Conclusion All twelve cases were treated successfully with cotherapy without any adverse pregnancy related events or adverse fetal outcomes. Intrauterine exposure of the fetus to thiopurine metabolites is not greater with combination therapy compared with thiopurine monotherapy. There are only two reports of congenital malformations with maternal allopurinol use. The case for an association based on two cases is weak, moreover a negative publication bias with respects to successful maternal allopurinal use is suspected. Our study provides support for clinicians and patients wishing to continue thiopurine-allopurinol co-therapy during pregnancy.

Disclosure of Interest None Declared.

\section{PTU-107 COMPARISON OF MORTALITY FOLLOWING HOSPITALISATION FOR ULCERATIVE COLITIS IN SCOTLAND BETWEEN 1998-2000 AND 2007-2009}

${ }^{1} \mathrm{NT}$ Ventham* ${ }^{*}$ 'NA Kennedy, ${ }^{2} \mathrm{~A}$ Duffy, ${ }^{2} \mathrm{DN}$ Clark, ${ }^{3} \mathrm{AM}$ Crowe, ${ }^{4} \mathrm{~A}$ Knight, ${ }^{5} \mathrm{JR}$ Nicholls, IJ Satsangi. 'Molecular Medicine Centre, University of Edinburgh, UK; ${ }^{2}$ eData Research and Innovation Service (EDRIS), Information Services Division of NHS Scotland, Edinburgh, UK; ${ }^{3}$ Corvus Ltd, Buxted; ${ }^{4}$ Evicom, Teddington; ${ }^{5}$ St Mark's Hospital, London, UK

\subsection{6/gutjnl-2014-307263.181}

Introduction We have previously demonstrated concerningly high 3-year mortality following hospitalisation with ulcerative colitis (UC) between 1998 and 2000 in Scotland. ${ }^{1}$ We have extended these studies by examining 3-year mortality following hospitalisation with UC in Scotland between 2007-2009, providing an opportunity for comparison with our earlier results.

Aim To compare 3-year mortality, and factors related to mortality, in Scottish patients hospitalised with ulcerative colitis (UC) between Period 1 (1998-2000) and Period 2 (2007-2009).
Methods The Scottish Morbidity Records and linked datasets were used to assess 3-year crude mortality, standardised mortality ratio (SMR) and multivariate analyses of factors associated with 3-year mortality. The 3-year mortality was determined after four admission types: surgery-elective or emergency; medicalelective or emergency. Age-standardised mortality rates (ASR) were used to compare mortality rates between periods.

Results The admission rate with UC increased from 10.6 per 100,000 of the Scottish population per year in Period 1 to 11.6 in Period $2(\mathrm{p}=0.046)$. Among those admitted with UC, the proportion aged $<30 y$ rs increased $(p=0.009)$. Crude and adjusted 3-year mortality fell between time periods (Crude $12.2 \%$ [Period 1] to $8.3 \%$ [Period 2], adjusted OR 0.59, CI 0.42 to $0.81, \mathrm{p}=0.04)$. Following emergency medical admission, 3 year mortality was reduced in Period 2 (OR $0.58, \mathrm{p}=0.003$ ). Within the $>65$ yrs age group crude 3 -year mortality fell $(38.8 \%$ to $28.7 \%, \mathrm{p}=0.02)$. The overall SMR in period 1 was 3.04 and 2.96 in Period 2.

Directly age standardised mortality decreased from 373 (CI $309-437$ ) to 264 (CI 212-316) per 10,000 person years. On multivariate analysis, older age and co-morbid remained associated with 3-year mortality in Period 2.

Conclusion Although the mortality associated with admission remains high at 3 years, crude and adjusted rates suggest significant reductions over the last decade.

\section{REFERENCE}

1 Nicholls RJ, Clark DN, Kelso L, et al. Nationwide linkage analysis in Scotland implicates age as the critical overall determinant of mortality in ulcerative colitis. Aliment Pharmacol Ther 2010;31:1310-21

Disclosure of Interest N. Ventham: None Declared, N. Kennedy: None Declared, A. Duffy: None Declared, D. Clark: None Declared, A. Crowe: None Declared, A. Knight: None Declared, J. Nicholls Grant/research support from: A grant was obtained from AbbVie Ltd to be administered by the North West London Hospital Trust (NWLHT) on behalf of Prof Nicholls, to allow funding of ISD and Corvus Communications for their work on the project. In the context of the work presented in this manuscript and in consideration of BMJ guidance, none of the authors have any competing or other conflict of interest, J. Satsangi: None Declared.

\section{PTU-108 CROHN'S DISEASE AND ANOGENITAL GRANULOMATOSIS PRESENTING WITH GENITAL OEDEMA}

${ }^{1} \mathrm{R}$ Mellor, ${ }^{1} \mathrm{~K}$ Gordon, ${ }^{1} \mathrm{P}$ Mortimer, ${ }^{2} \mathrm{R}$ Pollok*. 'Lymphoedema Service, St George's Hospital, London, UK, '2 Gastroenterology, St George's Hospital, London, UK

10.1136/gutjnl-2014-307263.182 